\title{
FERMENTATION OF BIOETHANOL FROM THE BIOMASS HYDROLYZATE OF OIL PALM EMPTY FRUIT BUNCH USING SELECTED YEAST ISOLATES
}

\author{
HENDRIQ FAUZAN KUSFANTO, BAITHA PALANGGATAN MAGGADANI, HERMAN SURYADI*
}

Laboratory of Microbiology and Biotechnology, Faculty of Pharmacy, Universitas Indonesia, Depok, Indonesia. Email: hermans001@yahoo.com

Received: 21 April 2017, Revised and Accepted: 18 August 2017

\section{ABSTRACT}

Objective: The purpose of this research was to investigate the potential of yeast-producing bioethanol from few type of grapes and durians.

Methods: The isolation of potential yeast was carried out from five different types of fruits, namely, red grape, black grape, durian Medan, durian Bangkok, and durian Monthong. Optimum fermentation condition was obtained by comparing shaking and non-shaking, detoxifying the hydrolysate, varying temperature, and concentration of $\mathrm{N}$ source in the culture medium.

Results: The results of an analysis using gas chromatography showed that the ideal conditions for the fermentation of bioethanol were at a temperature below room temperature $\left(+220^{\circ} \mathrm{C}\right)$, without shaking, using the hydrolysate, without detoxification, and with a $1 \%$ concentration of ammonium acetate as a source of N. Among the isolates, isolate DM1 obtained from durian Medan showed a strong potential to produce bioethanol but at lower levels than Saccharomyces cerevisiae. The concentration of ethanol produced was $0.241 \%$.

Conclusion: A yeast isolate with a strong potential to produce bioethanol was discovered as the DM1, which isolated from Medanese durian. The isolate produced $0.241 \%$ bioethanol. However, fermentation optimization efforts using an oil palm empty fruit bunch hydrolysate substrate did not yield higher concentrations.

Keywords: Bioethanol, Biomass, Ethanol, Fermentation, Hydrolysate, Isolation, Saccharomyces cerevisiae, Oil palm empty fruit bunch.

(C) 2017 The Authors. Published by Innovare Academic Sciences Pvt Ltd. This is an open access article under the CC BY license (http://creativecommons. org/licenses/by/4. 0/) DOI: http://dx.doi.org/10.22159/ijap.2017.v9s1.21_26

\section{INTRODUCTION}

Microorganisms or microbes are minuscule living organisms that are only observable by microscope. Microorganisms can be found everywhere, and their interactions can be advantageous or disadvantageous. The majority of microorganisms positively contribute to the balance in the environmental ecosystem and are beneficial for humankind in various fields, such as vital elements recycling, waste management, mining and industrial applications, modern biotechnology, pharmacy, and health [1]. In food technology, some microorganisms are identified as "generally recognized as safe." Some of the microorganisms that have been known for a long time and considered safe for consumption include Saccharomyces cerevisiae, Lactobacillus sp., Aspergillus sp., and Candida utilis.

Yeast is one of the well-known beneficial microorganisms. It is a round or oval-shaped, single-celled, non-filamentous, non-flagellated fungus that is larger than bacterial cells [1]. Yeast's roles in human life are mostly related to the food and fermentation industry. One of the most commonly used yeasts is $S$. cerevisiae. In food technology, S. cerevisiae can be used to create bread, wine, and tapai. Meanwhile, in the fermentation industry, it is usually used to produce bioethanol.

Alcohol or ethanol has many uses, for instance, as a raw material in manufacturing organic compounds such as acetic acid. In addition, alcohol can be used in organic materials, such as perfume, iodine tincture, camphor, and brand rectified spirits, and as a solvent in varnish manufacturing. In laboratories, alcohol is used to dilute polar compounds without triggering hydrolysis [2]. Alcohol fermentation is not only effective in food and beverage preservation but also for analgesics and disinfectants. It was once used as a component in preservatives [3]. In the medical field, especially in hospitals and other health service facilities, alcohol is used for topical and outer surface application due to its antiseptic and disinfectant uses. Alcohol is particularly useful and significant in infection control and aids in nosocomial prevention [4]. Meanwhile in pharmacy, alcohol is used as a solvent. Among pharmacy products, it is used as an elixir and in tincture drug form. Elixir is an oral solution drug form that has alcohol as a cosolvent; meanwhile, tincture is ethanol or a hydroalcohol-containing solution made out of plant or chemical compounds [5]. Ethanol also has the potential of becoming a next-generation renewable automobile fuel, such as lignocellulose biomass [6].

There are two generations of bioethanol (alcohol) production. Firstgeneration bioethanol is produced by processing food crops, such as corn. The drawback of the first-generation bioethanol is that it causes competition between food production and as bioethanol raw material for fuel, thus hiking the price. The second-generation bioethanol, however, is produced from food biomass, particularly from lignocellulose, as it is derived from non-food materials that are cheap and readily available from plants [7]. The second-generation bioethanol is more gainful because it not only uses biomass but also does not elicit competition with harvest crops. One of the most abundant non-food crops that are lignocellulose biomass sources in Indonesia is oil palm empty fruit bunch (OP-EFB). An 8.4 million hectare plantation can potentially generate 20 million tons of OP-EFB in wet conditions or 10 million tons in dry conditions. The cellulose content is quite high, about 41-47\%; therefore, one ton of EFB has the potential to produce $150 \mathrm{l}$ of ethanol, which becomes a huge number when multiplied by 10 million tons [8].

More and more research on bioethanol production is being conducted, but most of those studies are still using $S$. cerevisiae pure yeast isolate. Meanwhile, many more unisolated, unidentified, and unknown microorganisms could be used for this purpose. The role of microorganisms in many fields, such as medicine and pharmacy, has a profitable potential if developed. This research involves a search for other potential yeasts to be made into bioconverter. The potential yeasts are sought from grapes and durian fruit since they are both 
known to produce alcohol when overripe. Hence, they are expected to have potential yeast that could convert glucose into ethanol. In addition, bioethanol fermentation using selected yeasts can be optimized.

\section{METHODS}

The raw material used in this research is OP-EFB gathered from PT Kresna Duta Agroindo (Jelateng Estate), Jelateng Village, in Jambi Province. The microorganisms were collected from red grapes, black grapes, Medanese durian, Bangkok durian, and Monthong durian. S. cerevisiae from LIPI's Indonesian Culture Collection, Cibinong, was also used as comparison.

The medium used for isolate seeding was potato dextrose agar. Other media were also used to create inoculums, such as $0.25 \%$ yeast extract, $0.25 \%$ pepton, $3.3 \%$ glucose, $0.03 \% \mathrm{MgSO}_{4} \cdot 7 \mathrm{H}_{2} \mathrm{O}$, and $0.10 \% \mathrm{KH}_{2} \mathrm{PO}_{4}$. An amount of $200 \mathrm{~mL}$ of media was made in a $500 \mathrm{Ml}$ Erlenmeyer. About one dose of isolate colony was put into $10 \mathrm{~mL}$ of media. Then, the inoculums were developed by stirring at $120 \mathrm{rpm}$ for $12 \mathrm{hrs}$ (Fig. 1) [9].

The research process began by preparing two things: Finding isolates and preparing the substrate. Yeast isolates from the fruits were examined; meanwhile, the substrate from OP-EFB was utilized. Then, the fermentation condition was optimized from the selected isolates gathered from the complex isolates of OP-EFB.

The first thing to do in looking for yeast isolate is separating the microorganism from the fruit. The ripe fruit was cut using a sterile scalpel and put into test tubes, and then sterile Aquadest was added and then vortexed so that the yeast cells would detach from sample (if needed, the suspension can be diluted a few times to make it less thick). Next, the suspension was spread on a Petri dish with the medium by scraping [10]. Then, a single colony of isolate from the first culture was replanted on another Petri dish for purification. Afterward, a stock of culture was made on the tipped agar media. After few isolates were gathered, yeast identification was done by comparing it with S. cerevisiae and other yeasts in the literature. The next step was screening by establishing small-scale fermentation in the test tubes to find potential isolates to create bioethanol. The fermentation medium consisted of
$3.3 \%$ glucose as a carbon source, $2 \%$ pepton, and $1 \%$ yeast extract as a complex nitrogen source. The mixture was fermented for $72 \mathrm{hrs,} \mathrm{and}$ the resultant bioethanol was analyzed using gas chromatography (GC).

The OP-EFB was prepared by cutting it into pieces and then ground and mashed. The powdery form was then sifted using a 60-mesh sieve until smooth, and uniform OP-EFB powder was gathered. At this point, the OP-EFB powder was ready for hydrolysis. About $15 \mathrm{~g}$ of dry OP-EFB powder was mixed with $300 \mathrm{ml} \mathrm{H}_{2} \mathrm{SO}_{4} 4 \%$ and autoclaved for $1 \mathrm{hr}$ at $121 \pm 3^{\circ} \mathrm{C}$. Next, the mixture was kept at room temperature and strained 4-5 times until the filtrate appeared clear [11]. The resultant hydrolysate was detoxed using active carbon to remove the furfural from the hydrolysis process. Active carbon at a $2.0 \%$ concentration was added and reheated at $55^{\circ} \mathrm{C}$ and 3,000 rpm and then restrained [12]

The glucose concentration in the hydrolysate was determined using an ultraviolet (UV)-visible spectrophotometer. About $1 \mathrm{ml}$ of sample was put into test tubes along with $1 \mathrm{ml}$ of DNS reagent and reheated to $100^{\circ} \mathrm{C}$ for 15 minutes and then kept at room temperature. The wavelength with maximum absorbance was then measured [13].

After the potential yeast isolates and substrate were ready, the next step was fermentation optimization. Fermentation was optimized to determine the influence of stirring, changing the temperature, detoxifying, and altering the nitrogen source concentration. Fermentation was done with a total volume of $20 \mathrm{ml}$ of media in a 50-ml Erlenmeyer flask. The fermentation media used were $0.25 \%$ yeast extract (b/v) and $2 \%$ ammonium acetate $(\mathrm{b} / \mathrm{v})$. The $\mathrm{pH}$ value of the hydrolysate was adjusted to 5 . The mixtures were then incubated for $72 \mathrm{hrs}$. The added inoculum concentration was $5 \%$ of the entire fermentation volume [11].

The last step of this research was the final fermentation using the selected isolates with selected optimization conditions from the previous steps. In addition, fermentation using $S$. was compared with the resultant bioethanol.

Bioethanol was analyzed using GC. The GC (Shimadzu model GC-17A) utilized a flame ionization detector, CBP-10 $50 \mathrm{~m} \times 0.25 \mathrm{~mm}$ ID column,

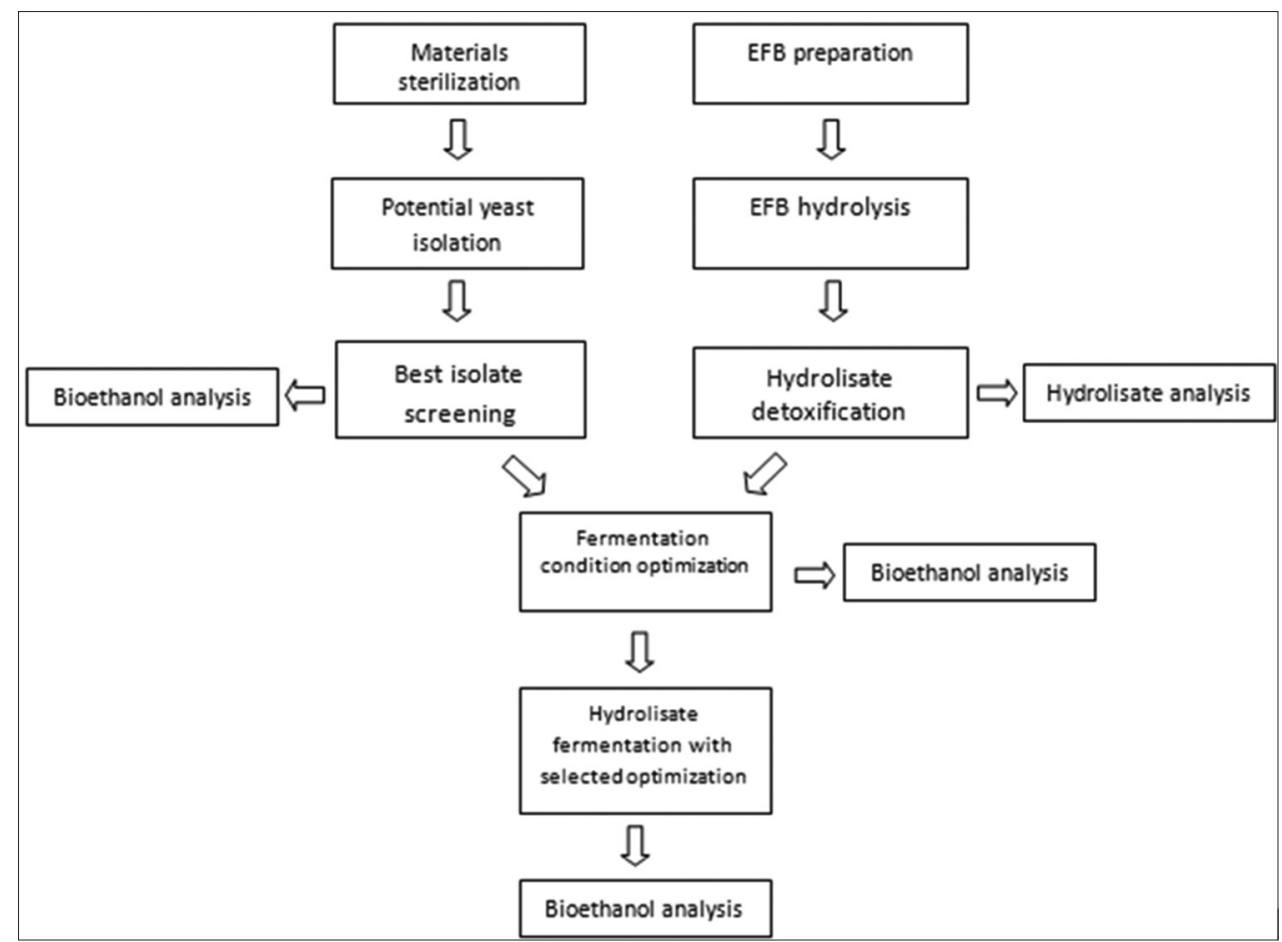

Fig. 1: Research method scheme 
CBM 102 integrator, and class GC solution data processor. The injector and detector temperature were maintained at $200^{\circ} \mathrm{C}$. Helium and hydrogen were used as carrier gases. The bioethanol concentration was calculated using the elution time and identified ethanol standard area. A summary of the chromatography system follows:

- Injector temperature: $200^{\circ} \mathrm{C}$

- Detector temperature: $200^{\circ} \mathrm{C}$

- Column temperature: $70^{\circ} \mathrm{C}$

- Flow rate: $1.2 \mathrm{ml} / \mathrm{minute}$

- Injection volume: $1 \mu \mathrm{l}$

- Carrier gases: Hydrogen and helium.

Before the analysis, a linearity test for concentration determination and calibration curve was calculated. The sample concentration was determined by putting $1 \mathrm{ml}$ of sample into a microtube using an Eppendorf pipette. The sample was centrifuged using a centrifugator at $10,000 \mathrm{rpm}$ for 5 minutes. Afterward, $1 \mu \mathrm{l}$ of sample filtrate was injected into a GC. The resulting area value gathered from the GC analysis was measured using the calibration curve linear line formula.

\section{RESULTS}

Fourteen colonies of the five fruits used were gathered in this research with the description as follow: Four colonies of red grapes (AM1, AM2, AM3, and AM4), one colony of black grapes (AH1), four colonies of Medanese durian (DM1, DM2, DM3, and DM4), three colonies of Bangkok durian (DB1, DB2, and DB3), and two colonies of Monthong durian (DMo1 and DMo2). Then, at the identification stage, the AH1 colony was removed since it macroscopically appeared more like mold than yeast (Fig. 2).

A system suitability test was done by injecting $1 \mu \mathrm{l}$ of standard ethanol with $9.99 \%$ concentration six times until the $\mathrm{KV}$ value reached $0.72 \%$, fulfilling the standard (below $2 \%$ ). A linearity test for ethanol concentration determination resulted in an $r$ value of 0.999 .

The isolate screening test results showed that not every isolate produced bioethanol. About four samples of isolate (AM1, AM2, AM4, and DB2) did not produce bioethanol. Meanwhile, the other nine did produce bioethanol, although none produced more bioethanol from the Indonesian Culture Collection LIPI in Cibinong (Fig. 3).

From the OP-EFB hydrolysis analysis, an end $\mathrm{pH}$ of 5.10 was gained after an adjustment with $10 \mathrm{~N} \mathrm{NaOH}$. The hydrolysate was divided into two samples. The first hydrolysate was detoxified with active carbon; meanwhile, the second hydrolysate was not. The division of the two hydrolysate groups was done to determine the influence of fermentation optimization by detoxification. From an analysis using a UV-visible spectrophotometer on both hydrolysates, the glucose concentrations of both were identified. The glucose concentrations were $3.19 \%$ from the detoxified hydrolysate and $3.45 \%$ for the non-detoxified hydrolysate.

As for the influence of stirring on fermentation optimization, more bioethanol was produced in the fermentation process without stirring (by $0.027 \%$ ) while fermentation using stirring did not produce any ethanol (Fig. 4).

In terms of the influence of temperature on the fermentation optimization, more bioethanol was produced at a temperature lower than room temperature $\left( \pm 22^{\circ} \mathrm{C}\right)$ by $0.028 \%$. Meanwhile, fermentation at room temperature $\left( \pm 28^{\circ} \mathrm{C}\right.$ ) yielded bioethanol by only $0.024 \%$ (Fig. 5).

For the influence of detoxification on fermentation optimization, more bioethanol was produced by non-detoxified hydrolysate, with an amount of $0.043 \%$. Meanwhile, hydrolysate with detoxification yielded 0.030\% ethanol (Fig. 6).

In terms of the influence of $\mathrm{N}$-source concentration on fermentation optimization, most bioethanol was produced by hydrolysates with an ammonium acetate concentration of $1 \%(0.241 \%$ of bioethanol),

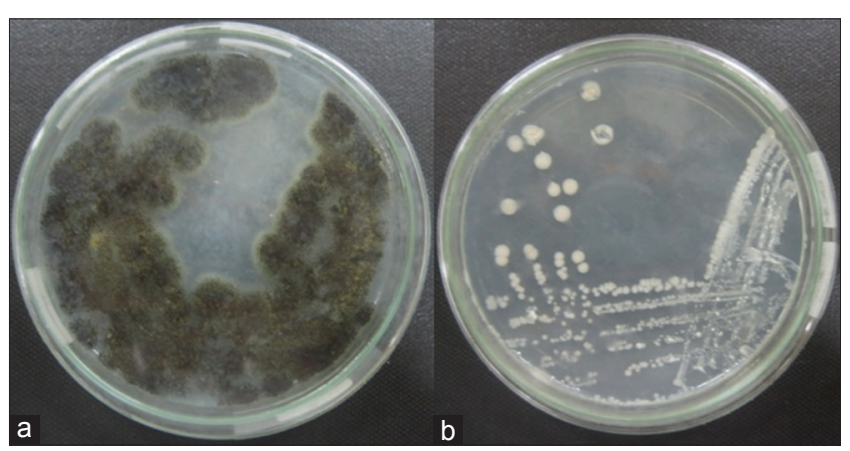

Fig. 2: Macroscopic appearance of isolate samples, (a) AH1 isolate, (b) DMO1 isolate

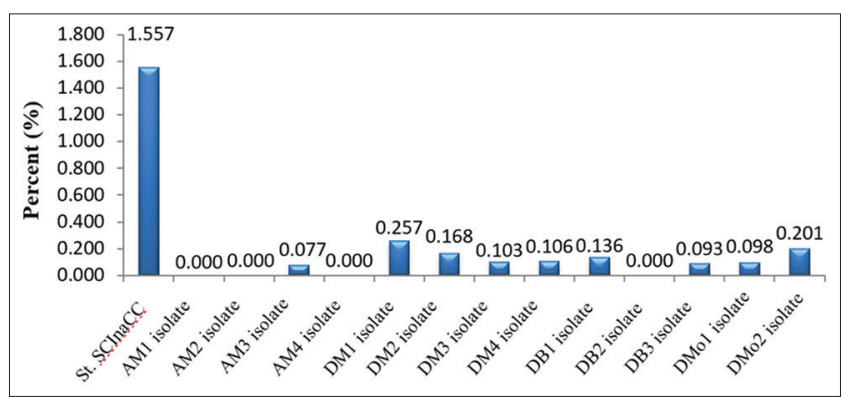

Fig. 3: Resultant bioethanol comparison from the isolated screening

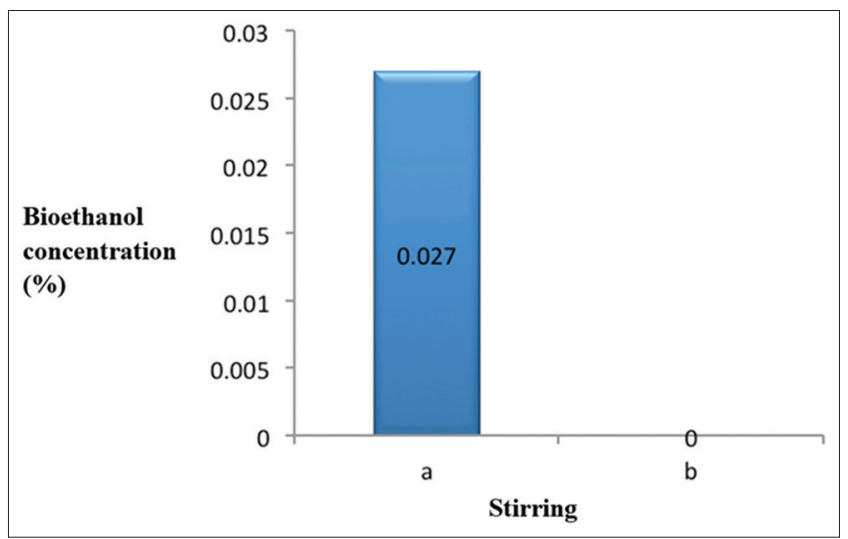

Fig. 4: Bioethanol concentration comparison from fermentation with and without stirring (a) without stirring ( 0 rpm), (b) with stirring (130 rpm)

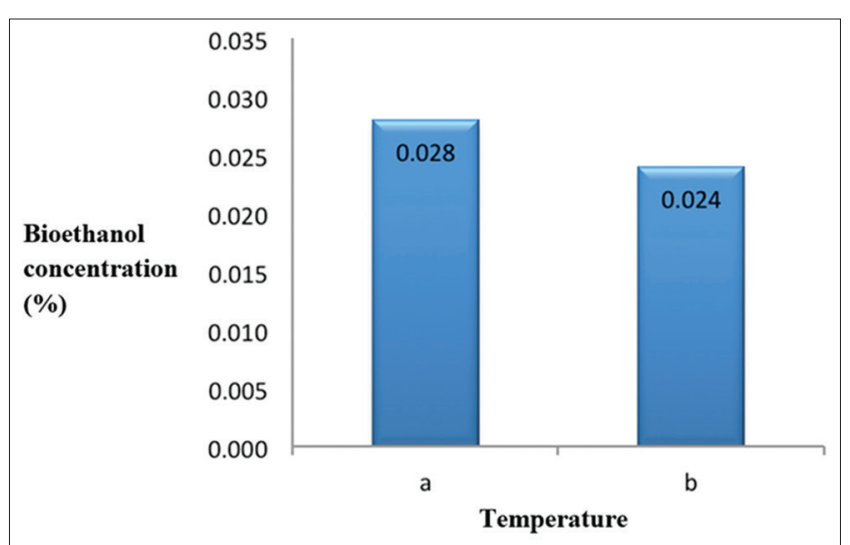

Fig. 5: Bioethanol concentration comparison from temperature optimized fermentation. (a) Below room temperature $\left( \pm 22^{\circ} \mathrm{C}\right)$, (b) on room temperature $\left( \pm 28^{\circ} \mathrm{C}\right)$ 
followed by $2 \%$ ( $0.213 \%$ of bioethanol), and 3\% (0.198\% bioethanol) (Fig. 7).

During the end stage, the DM1 isolate could produce $0.195 \%$ bioethanol, compared to about $0.203 \%$ produced by S. cerevisiae. The end result of bioethanol attained from the DM1isolate and the compared yeast was similar (Fig. 8).

\section{DISCUSSION}

Out of the 14 isolates, one was macroscopically clear as non-yeast, which was the AH1 isolate. The AH1 isolate appeared black and had mycelium-

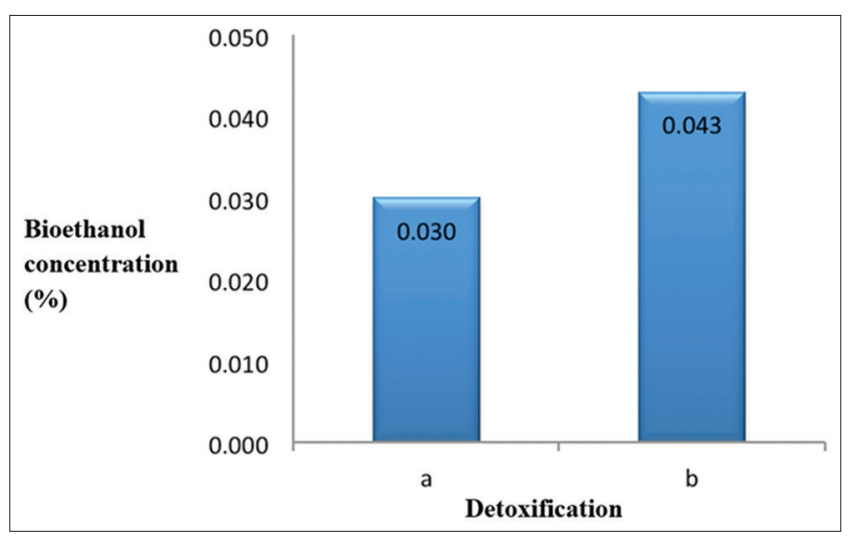

Fig. 6: Bioethanol concentration comparison from detoxification optimized fermentation (a) detoxified hydrolysate,

(b) non-detoxified hydrolysate

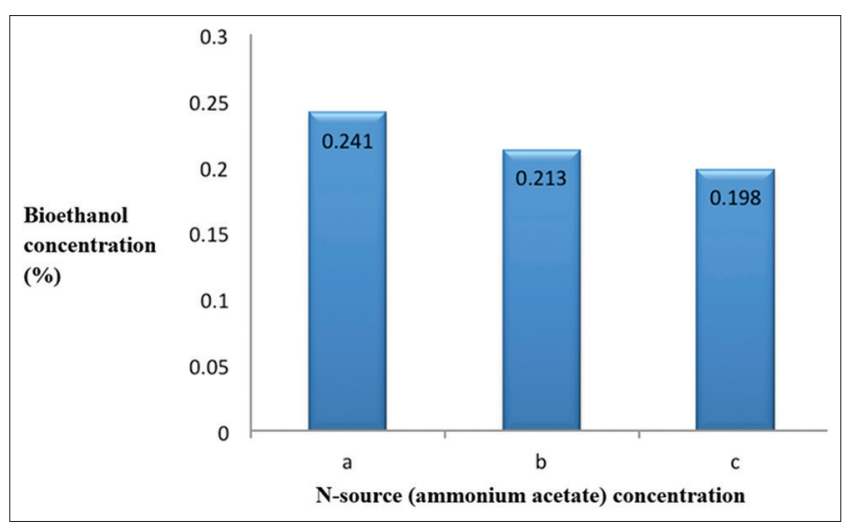

Fig. 7: Bioethanol concentration comparison from $\mathrm{N}$-source (ammonium acetate) concentration-optimized fermentation (a) $1 \%$, (b) $2 \%$, (c) $3 \%$

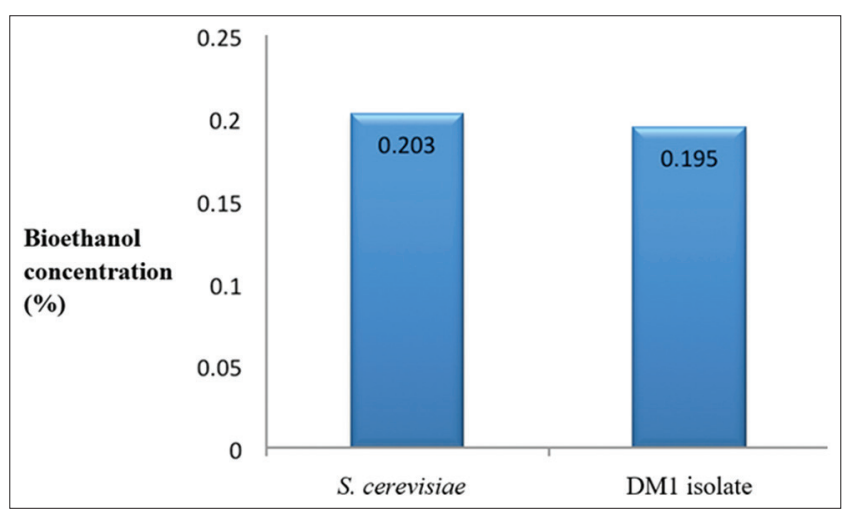

Fig. 8: Bioethanol concentration comparison fermented by Saccharomyces cerevisiae and DM1 isolate like strands; therefore, it seemed to be more of a mold than yeast (Fig. 2). Meanwhile, the other isolates appeared more like an S. cerevisiae colony. A microscopic comparison among isolates was done by matching the isolates with the literature on several species of yeast $(S$. cerevisiae, Pichia stipitis, and Candida shehatae). The result shows a resemblance between isolate microorganisms with S. cerevisiae, although not similar. The $S$. cerevisiae cells were round or oval shaped with various sizes. The cells on several isolates, such as in the DM1 isolate, were also round or oval shaped, resembling S. cerevisiae and P. stipitis. Some isolates, such as the DMO2 isolate, were longer, resembling $C$. shehatae. In this stage, the AH1 isolate was removed due to its macroscopic distinction, and the other 13 moved on to the screening stage.

During the isolate screening stage, the isolates that did not produce bioethanol came from grapes. This might be due to the fact that the grapes were purchased from a fruit market instead of a field; hence, they may have already been washed and cleaned. If so, the yeasts on the fruit skin may have been removed. In addition, the preservatives on the grapes could also cause the disappearance of the yeast on the grape skin. The grapes should have been purchased directly from the field to ensure that the yeasts on the grape skin remained. The grapes should be selected by taking several different varieties during harvesting [14].

The isolates that could only produce $<0.2 \%$ of bioethanol are considered to have no potential, and those that produced more than $0.2 \%$ bioethanol are considered to have a good potential. From the nine bioethanolproducing isolates, two isolates (DM1 and DMO2) showed a good potential. The DM1 isolate produced up to $0.257 \%$ bioethanol, and DMO2 produced $0.201 \%$ bioethanol. Therefore, the DM1 isolate was designated as the selected isolate in this research. Fermentation optimization should increase the bioethanol concentration production from the DM1 isolate.

A gap was observed in the glucose concentration between the detoxified hydrolysate and non-detoxified hydrolysate samples. The result showed a higher glucose concentration in the non-detoxified hydrolysates than in the detoxified hydrolysates, which demonstrates the influence of active carbon on glucose concentration. Glucose concentration reduction during the detoxification process could also be caused by the carbon adsorbing the substrate rather than the furfural [12].

In terms of the influence of stirring on fermentation optimization, fermentation without stirring produced more bioethanol than with stirring. The stirring process could not produce bioethanol due to the flow rate created. An increase in the flow rate caused a reduced contact time between the isolate-produced enzymes with a glucose substrate; therefore, no bioethanol was created. In additiona, stirring causes the dilution of oxygen, therefore inhibiting the fermentation process.

For the influence of temperature on fermentation optimization, lower temperatures yielded more bioethanol. According to Sa'id [2], when the temperature is lowered, the fermentation process should be better since less alcohol is evaporated. This goes in hand with the study by Kassim et al. [15], which stated that higher temperatures would interfere with ethanol production by inhibiting enzymes, changing the cell membrane structure, and deteriorating its function to produce ethanol. Moreover, higher temperatures could produce acetic acid, glycerol, succinic acid, and acetaldehyde, which are known to be toxic to yeast cells and to reduce ethanol production [15].

In terms of the influence of detoxification on fermentation optimization, fermentation with non-detoxified hydrolysate yielded more bioethanol than the detoxified counterpart. Detoxified hydrolysates were expected to absorb toxins from the hydrolysis process, so they should not interfere with bioethanol production by yeast cells. However, the result was non-significant, but the difference in glucose concentration in both hydrolysates impacted the resultant bioethanol.

For the influence of $\mathrm{N}$-source concentration on fermentation optimization, ammonium acetate was chosen because it has an ammonium ion, which 
is usually used as a nitrogen source on fermentation media. Moreover, ammonium acetate was chosen due to its economic value rather than pepton, which has an $\mathrm{N}$-complex composition. The fermentation optimization with $\mathrm{N}$-source modification showed that $1 \%$ of ammonium acetate was enough to produce optimum bioethanol. However, the addition of a greater ammonium acetate concentration would reduce the amount of bioethanol product. The bioethanol concentration reduction might be caused by the disturbance of yeast cells in an environment saturated with $\mathrm{N}$, therefore inhibiting bioethanol production. An ammonium ion $\left(\mathrm{NH}_{4}^{+}\right)$used as an $\mathrm{N}$ source by yeast cells would leave an acetate ion behind $\left(\mathrm{CH}_{3} \mathrm{COO}\right)$. These acetate ions could be a precursor for acetic acid formation, which is known to be toxic for yeast cells [15].

In the final stage, fermentation was done using the selected isolate (DM1) on selected optimization conditions, and then the result was compared with the result from $S$. cerevisiae to determine the effectiveness of the DM1 isolate. The comparison showed similar results between the final bioethanol product from $S$. cerevisiae and from the DM1 isolate. This proves that the DM1 isolate using OP-EFB complex carbon hydrolysate has quite a strong potential to produce decent bioethanol amounts compared to $S$. cerevisiae.

For both the DM1 isolate and S. cerevisiae, bioethanol production was no larger in the final stage than in the screening stage. Fermentation condition optimization did not manage to increase the produced bioethanol concentration, which might be due to several factors:

1. During the screening phase, the carbon source was glucose; meanwhile, during the final stage, the carbon source was switched to the OP-EFB hydrolysate. Lower bioethanol production was caused by the inhibitor components in the OP-EFB hydrolysate.

2. The fermentation media during the screening stage contained more nutrition than during the final stage. In the screening stage, the nutrition was provided by $1 \%$ yeast extract and $2 \%$ pepton. Meanwhile, during the final stage, the nutrition used was from $0.25 \%$ yeast extract and $2 \%$ ammonium acetate.

Although both processes were done in anaerobic conditions, the residual air volume from both stages was different, which was caused by the differences in type and size of the fermentation volume. During the final stage, an Erlenmeyer flask was used, resulting in higher air volume than during the screening stage, which used test tubes. The higher residual air volume resulted in more oxygen, which could inhibit the fermentation process.

\section{CONCLUSION}

A yeast isolate with a strong potential to produce bioethanol was discovered from isolation: The DM1 isolate from Medanese durian. The isolate produced $0.241 \%$ bioethanol. However, fermentation optimization efforts using an OP-EFB hydrolysate substrate did not yield higher concentrations. The researcher hopes to further explore more potential yeast isolates. In the future, potential yeast growth optimization also needs to be examined. In addition, the use of other substrates or combinations of substrates can be considered along with hydrolysis optimization so that the resultant substrates can be larger. To yield more optimum bioethanol, fermentation optimization by modifying the $\mathrm{pH}$ condition, substrate concentration on hydrolysates, and fermentation time can also be done.

\section{REFERENCES}

1. Pratiwi ST. Mikrobiologi Farmasi. Jakarta: Penerbit Erlangga; 2008

2. Sa'id EG. Bioindustri Penerapan Teknologi Fermentasi. Jakarta: PT Melton Putra; 1987.

3. Marsit S, Dequin S. Diversity and adaptive evolution of Saccharomyces wine yeast: A review. FEMS Yeast Res 2015;15. pii: fov067.

4. McDonnell G, Russell AD. Antiseptics and disinfectants: Activity, action, and resistance. Clin Microbiol Rev 1999;12:147-79.

5. Departemen Kesehatan RI. Farmakope Indonesia. $4^{\text {th }}$ ed. Jakarta: Direktorat Jenderal Pengawasan Obat dan Makanan; 1995.

6. Kumar S, Singh SP, Mishra IM, Adhikari DK. Recent advances in production of bioethanol from lignocellulosic biomass. Chem Eng Technol 2009;32:517-26.

7. Naik SN, Goud VV, Rout PK, Dalai AK. Production of first and second generation biofuels: A comprehensive review. Renew Sustain Energy Rev 2010;14:578-97.

8. Kemenristek. Pemanfaatan Bioetanol Untuk Kebutuhan Energi Indonesia. Available from: http://www.ristek.go.id/index.php/module/ News+News/id/10973.

9. Sudiyani Y, Styarini D, Triwahyuni E, Sudiyarmanto S, Sembiring KC, Aristiawan Y, et al. Utilization of biomass waste empty fruit bunch fiber of palm oil for bioethanol production using pilot-scale unit. Energy Procedia 2013;32:31-8.

10. Gandjar I, Sjamsuridjal W. Mikologi: Dasar dan Terapan. Jakarta: Yayasan Obor Indonesia; 2006

11. Asli U, Hamid H, Zakaria Z, Sadikin N, Rasit R. Fermentable sugars from palm empty fruit bunch biomass for bioethanol production. Int $\mathrm{J}$ Chem Nucl Metall Mater Eng 2013;7:607-10.

12. Mutsnaini L. Optimization xylitol production from xylose with variation of substrate concentration aeration and metal ion addition utilizing oil palm empty fruit bunch hydrolyzates with Debaryomyces Hansenii. Universitas Indonesia; 2013.

13. Rosikhoh D. Isolation of cellulolytic mold and characterization of microcrystalline cellulose from oil empty fruit bunch results of enzymatic hydrolysis of cellulose. Universitas Indonesia; 2014.

14. Li SS, Cheng C, Li Z, Chen JY, Yan B, Han BZ, et al. Yeast species associated with wine grapes in China. Int J Food Microbiol 2010;138:85-90.

15. Kassim MA, Kheang LS, Bakar NA, Aziz AA, Som RM. Bioethanol production from enzymatically saccharified empty fruit bunches hydrolysate using Saccharomyces cerevisiae. Res J Environ Sci 2011;5:573-86 